\title{
THE ULTRASTRUCTURE OF THE CIVET GLAND IN SMALL INDIAN CIVET (VIVERRICULA INDICA)
}

\author{
Francis Xavier ${ }^{1}$ and M. Balakrishnan ${ }^{2}$ \\ ${ }^{1}$ College of Veterinary and Animal Sciences, Kerala Agricultural University, Mannuthy, Trichur, Kerala 680651, India \\ 2 Department of Zoology, University of Kerala, Kariavattom, Thiruvananthapuram, Kerala 695581, India
}

\begin{abstract}
The modified skin gland of Small Indian Civet (Viverricula indica) located at the perineal region has been studied for its ultrastructure. The 'civet gland' found in both the sexes secrete the prized item 'civet' which has a wide use in indigenous medicines and oriental perfumes. In this preliminary study of the gland, holocrine mode of secretion is established. Large lipid droplets were found filling the cells which were disintegrating holocrine secretory cells. A centrally placed nucleus and nucleolus could be located in developing cells. Smooth endoplasmic reticulum whirls were also observed. The secretion of this gland plays an important role in the chemical communication system of this small mammal.
\end{abstract}

\section{Key Words}

Civet gland, ultrastructure, perineal gland, Small Indian Civet

\section{Introduction}

Chemical communication plays an important role in the biology of mammals (Gorman, 1990). The dazzling array of odoriferous skin glands in mammals are utilized in transmission of information and mammals are often profligate in their use of social odours. Many mammalian species own complex glandular organs exclusively developed for secretion of chemical components which are either chemical signals themselves or are transformed into such signals by microbial activity (Schliemann et al., 1985). Information on the structure perineal gland of Small Indian Civet is scanty although its secretion is used from very early times in indigenous medicines and in oriental perfumes (Kingston, 1964; Xavier. 1993a,b; Xavier \& Balakrishnan, 1993a,b). Small Indian Civets have conspicuous glandular organs lying between the anus and the opening of the excretory and reproductive organs. Only some baseline information on the functional significance of their gland are available (Xavier 1993a,b; 1994; Xavier \& Balakrishnan, 1993a,b,c). The secretion 'civet', which is obtained from males and females, is widely used in our country. Considering the wide use of the secretion and the role of civets as a sustainable wildlife resource, a preliminary study on the ultrastructure of this largest developed skin gland of Small Indian Civets was taken up.

Received 15 April 1999;
Accepted 21 September 1999

\section{Materials and Methods}

Perineal glands from 10 male and 10 female Small Indian Civets kept in captivity were utilized for the present study.

The animals were kept under 'Ketamine-Xylazine' anaesthesia. The perineal gland region was shaved and cleaned with a mild antiseptic lotion. Vertical and horizontal incisions were made to expose the glandular tissue. Tissue samples of approximately $10 \times 10 \mathrm{~mm}$. were collected. The incision was closed by surgical suture. All the animals underwent an uneventful recovery.

The tissue samples were sliced into very small pieces and fixed in 2.5 per cent gluteraldehyde in $0.1 \mathrm{M}$ sodium cacodylate buffer (pH 7.2) at room temperature. This was post-fixed in one per cent osmium tetroxide in the same buffer. The tissue samples were then processed for electron microscopy. It was dehydrated in acetone series and embedded in 'araldite 502'. Ultra thin sections were cut using a 'LKB ultramicrotome'. Sections were stained with uranyl acetate and lead citrate and observed under a 'Philipps EM 400' electron microscope.

\section{Results and Discussion}

The perineal gland of Small Indian Civet is distinctly visible between the anus and the opening of the reproductive organs of both males and females. This conspicuous glandular organ is covered by hair and has two bulging halves with a central cleft. Each half can be seen as a round intact mass when incised. 


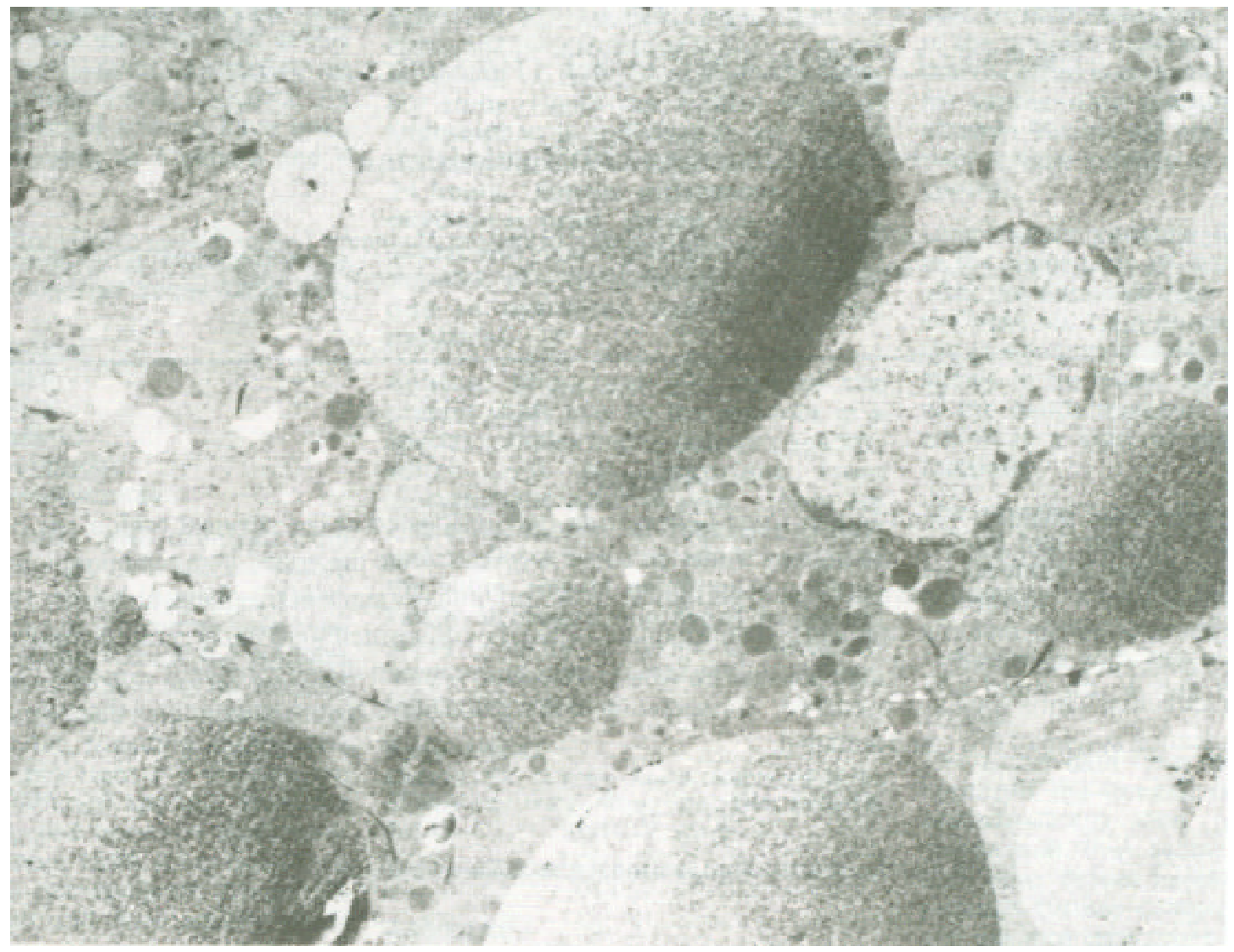

Figure 1. Electron micrograph of a secretory cell with lipid droplets in the perineal gland of Small Indian Civet. Large secretaory droplets of 2-5 $\mu \mathrm{m}$. in diameter are filling the mature cell. Note the absence of the nucleus.

The incised perineal gland revealed the appearance of honeycomb like construction. The interspace was filled with yellowish oily secretory material and it oozed out as soon as each glandular tissue mass was cut.

Simple histological sections revealed a conglomeration of secretory mass separated by connective tissue. Holocrine secretory units formed this secretory mass (Xavier, 1994). Electron micrograph of the secretory cells revealed large lipoid secretory droplets of about 2 to $5 \mu \mathrm{m}$. in diameter filling the cells (Figure 1). Similar large cells filled with lipid droplets formed the central part of the alveoli. These were the disintegrating holocrine secretory cells. The developing cells, i.e. the basal layer of thin flat epithelial cells lining the periphery, showed secretory droplets of about $0.2 \mu \mathrm{m}$. in size. These cells have a centrally placed round nucleus and the nucleolus is also visible (Figure 2 ). Smooth endoplasmic reticulum whirls are found in these cells (Figure 3).

The prominent and specialized integumentary gland located in the perineal region of the Small Indian Civet is almost similar to the cutaneous scent glands described in other mammalian spe- cies like African civets, Chinese civets (Jacob \& Schliemann, 1983, 1986) and Indian Musk Shrew (Balakrishnan, 1987). The present observation of large secretory droplets in the mature cells, is in agreement with the reports of Dellman (1993) that the sebaceous glands are simple branched or compound alveolar glands that release their secretory products by holocrine mode. In mature cells, the lipid droplets fill the entire cell to such an extent that other cell structures either become invisible or move to the periphery of the cells. The entire cells in the holocrine mode of secretion disintegrates and the contents are extruded into the duct.

\section{Conclusion}

Although the secretion from the perineal gland of male and female civets are used in indigenous medicine and oriental perfumes from very early times, elaborate studies on this gland and its structure are meagre. In the present preliminary study on the ultrastructure of this modified perineal gland, holocrine mode of secretion is establised. Secretory droplets of about 2 to $5 \mu \mathrm{m}$. in diameter filling the mature cells prove that the civet gland is a modified holocrine skin gland. The basal layer of thin flat epithelial cells lining the periphery showed smaller secretory drop- 


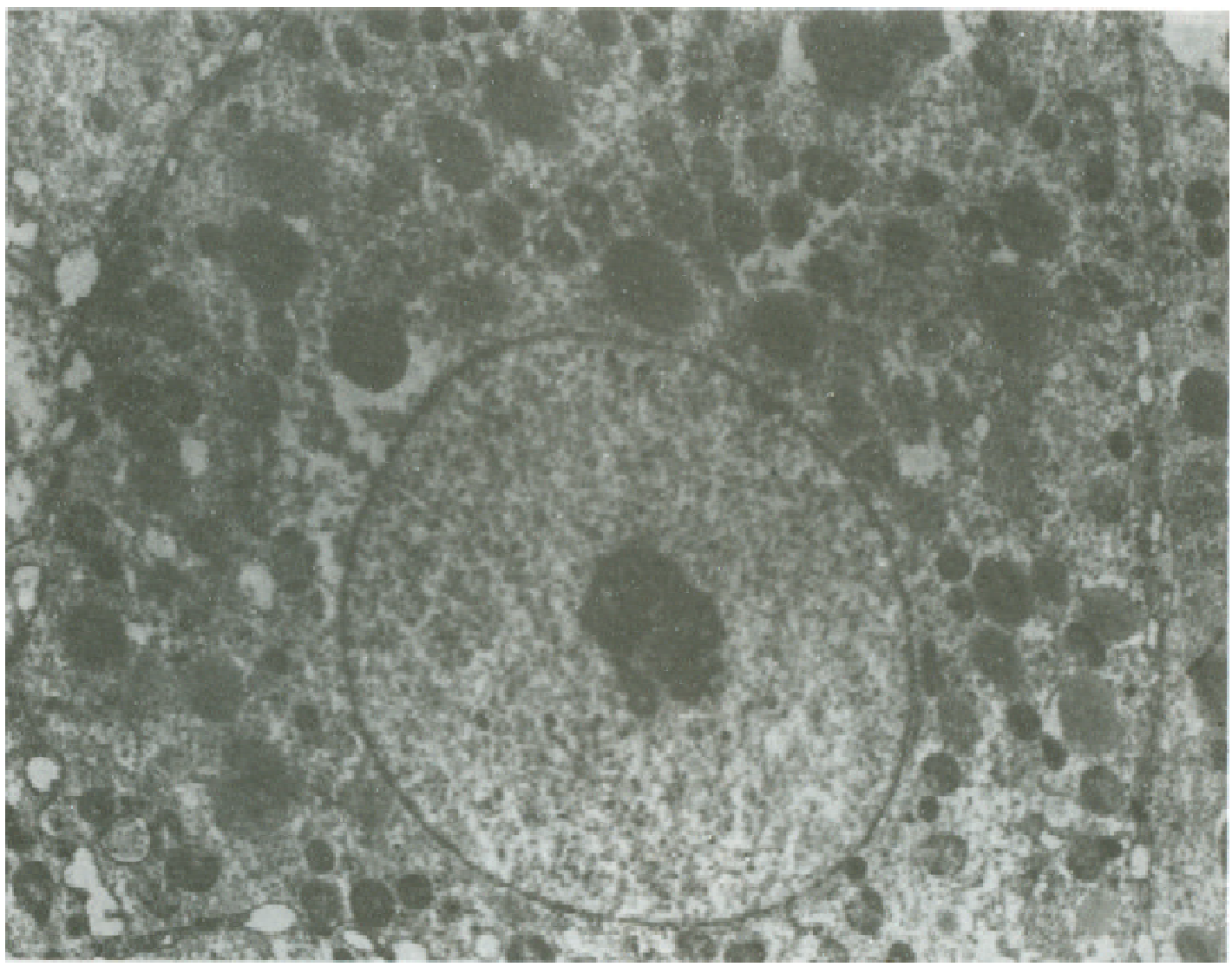

Figure 2. Electron micrograph of a basal cell with small secretory droplets of $0.2 \mu \mathrm{m}$. in size distributed around the nucleus. The nucleus with a central nucleolus may be noted in the centre of this cell.

lets of about $0.2 \mu \mathrm{m}$. in size with a centrally placed nucleus and nucleolus. There was no sexual dimorphism as far as the ultrastructure of the gland is concerned.

\section{References}

Balakrishnan, M. (1987). Light and electron microscopic observation on lipid droplets of the sebaceous flank gland of the shrew, Suncus murinus viridescens (Blyth) Proc. Indian Acad. Sci. (Anim. Sci) 96: 33-40.

Dellmann, H.D. (Ed.). (1993). Text Book of Veterinary Histology. Fourth ed. Lea and Febiger, Pheladelphia.

Gorman, M.L. (1990). Scent marking strategies in mammals. Revve. Suisse. Zool., 97: 3-29.

Jacob, J. and H. Schliemann (1983). Chemical composition of the secretion from the anal sacs of Civettictis civetta z. Naturforsch. 38: 497-500.

Jacob, J. and H. Schliemann (1986). The anal sac secretion of viverrids from the genus Genetta. z. Naturforsch. 41: 325-336.

Kingston, B.H. (1964). The chemistry and olfactory properties of musk, civet and castoreum. Proc. Second. Int. Cong. Endocrinology. Part I: 209-214.

Schliemann, H., J. Jacob and F.I.B. Kayanja (1985). Vergleichendmorphologische und-biochemische unter suchungen and Anal beut eln von schlerchkatzen. Funkt. Biol. Med. 5: 319.
Xavier, F. (1993a). Civet cats - A sustainable wildlife Resource. Contemporary Zoology 1: 177-186.

Xavier, F. (1993b). Status and Management Survey of Small Indian Civets and Captivity. Zoo's Print, 18: 1-16.

Xavier, F. (1994). A study on small Indian Civet as a Sustainable Wildlife Resource. Ph. D Thesis (submitted to Univ. of Kerala).

Xavier, F. and M. Balakrishnan (1993a). Civet cats captive population-husbandry and management. Proc. Fifth. Kerala Sci. Cong. pp 434-437.

Xavier, F. and M. Balakrishnan (1993b). Ethogram of captive small Indian civets. Proceedings of Twentyfirst annual conference and national colloquium on perspectives in Animal Behaviour. Tirupathi. A.P. : 3.

Xavier, F. and M. Balakrishnan (1993c). Breeding behaviour of captive small Indian civet. Proceedings all India Symposium on ethology and wildlife Silent valley, Kerala: 48. 


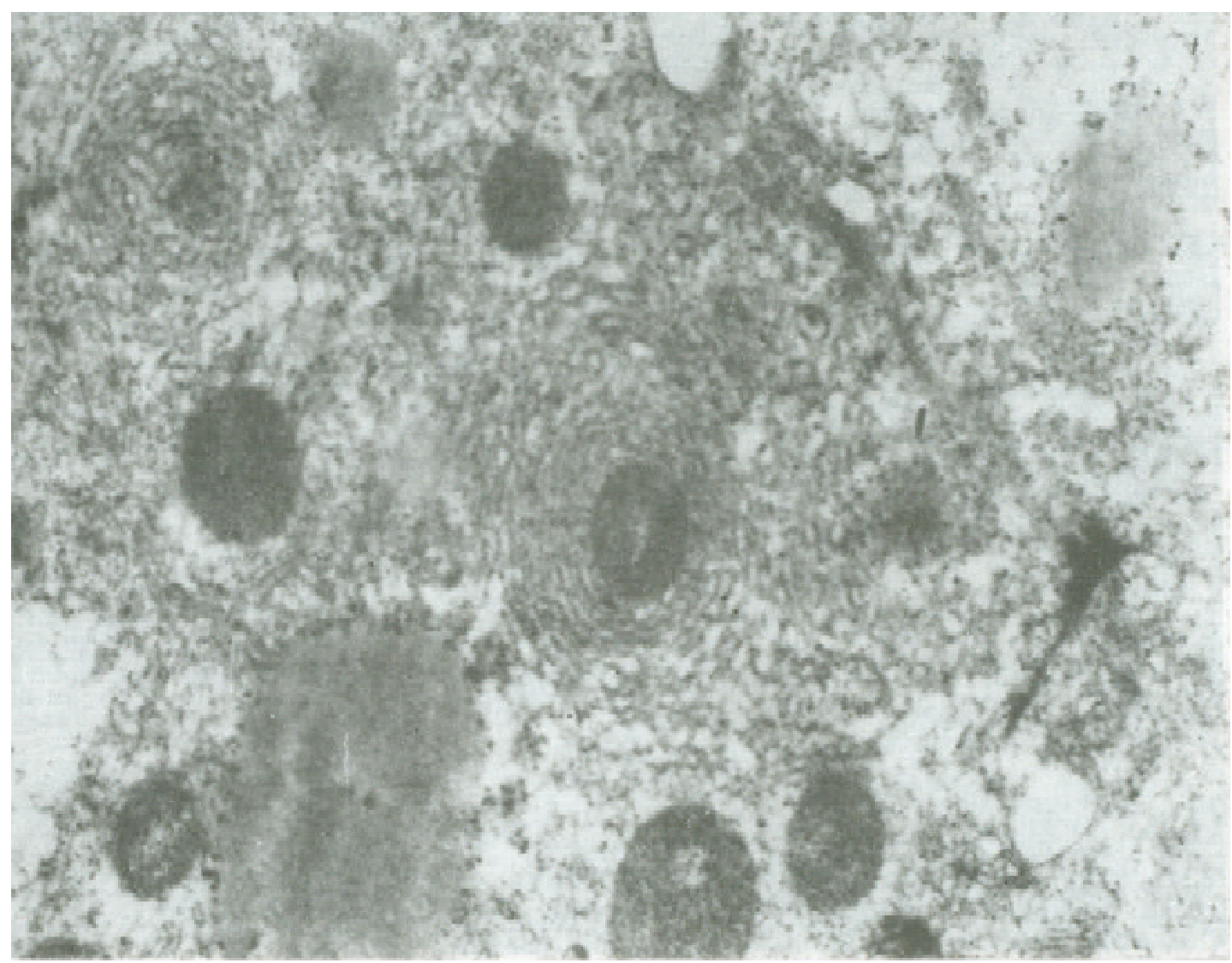

Figure 3. The secretory cell from the perineal gland of Small Indian Civet with smooth endoplasmic reticulum whirls and lipid droplets. 